\title{
EXCLUSIVE USE OF DILTIAZEM IN THE PER-OPERATIVE MANAGEMENT OF BILATERAL PHAEOCHROMOCYTOMA:
}

CALDEIRA A., GALACHO J., PEREIRA I.

ANAESTHETIC DOUBLE CHALLENGE

CENTRO HOSPITALAR LISBOA NORTE, EPE

DEPARTMENT OF ANAESTHESIOLOGY I LISBON, PORTUGAL

This study aims to report the exclusive use of diltiazem in the per-operative anaesthetic management of a patient with bilateral phaeochromocytoma.

The phaeochromocytoma patient approach should be done by a multidisciplinary team with the early anaesthesiologist involvement. Alpha and beta-blockade play an essential role in the preoperative management of these patients.

CASE REPORT: A 29-year-old asymptomatic male, with multiple endocrine neoplasia (MEN) type 2B syndrome, was admitted for bilateral laparoscopic adrenalectomy.

Diagnostic was confirmed by abdominal CT scan, MIBG scan and raised urinary cathecolamines.

Blood pressure $(\mathrm{BP})$ and heart rate $(\mathrm{HR})$ were within normal range. Preoperative management strategy was diltiazem 60mg once daily, seven days before surgery.

Premature ventricular contractions, major intraoperative $\mathrm{BP}$ and $\mathrm{HR}$ fluctuations occurred during the manipulation of both tumours, followed by abrupt falls on BP and HR.

DISCUSSION: Phaeochromocytoma's pre-operative management and patient optimization are core aspects, as mortality rate can reach up to $50 \%{ }^{1}$, and they aim for adequate BP, HR and arrhythmias control, restore volume depletion and prevent induced catecholamine storm. ${ }^{2}$

There is still no consensus on the best approach, although the alpha adrenergic blockade for at least 2 weeks seems to be the most commonly used strategy. Once the patient is adequately prepared, beta blockade can then be instituted.

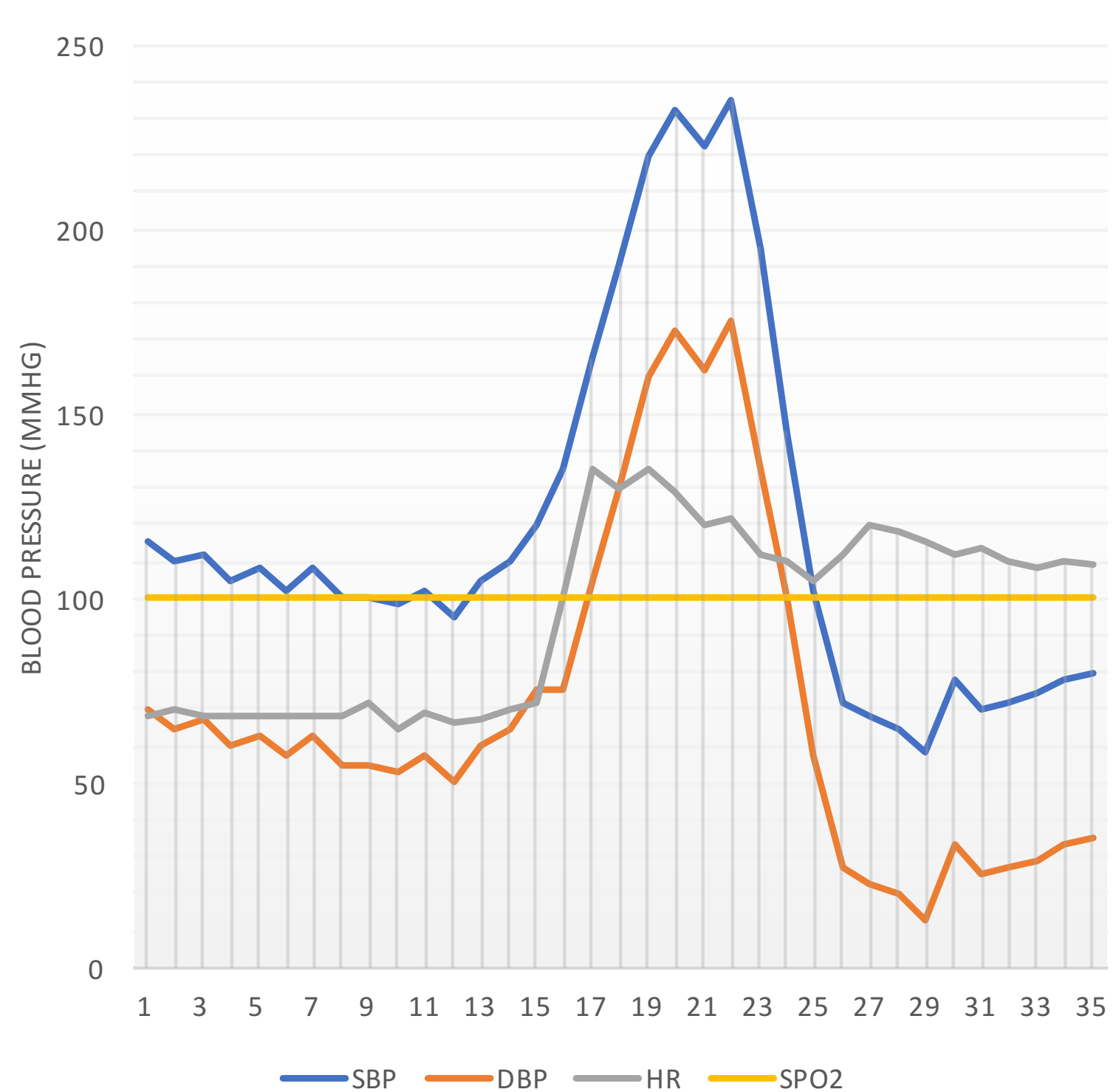

Figure 1. BP and HR fluctuations during first tumour manipulation.

No distinction was found in hypertensive episodes during surgery for MEN and non-MEN-associated phaeochromocytoma. As such, management with alpha and beta-adrenergic blockers remains a standard of care in both groups. 3

In spite of lacking morbidity or mortality, our case represents how challenging a normotensive asymptomatic phaeochromocytoma can be.

\section{REFERENCES:}

1.Desmonts JM, le Houelleur J, Remond P, Duvaldestin P. Anaesthetic management of patients with pheochromocytoma: A review of 102 cases. Br $\mathrm{J}$ Anaesth. 1977;49:991-8

2.Bajwa SS, Bajwa SK (2011) Implications and considerations during pheochromocytoma resection: A challenge to the anesthesiologist. Indian J Endocrinol Metab 15: S337-S344.

3.Scholten A, Vriens MR, Cromheecke GJ, Borel Rinkes IH, Valk GD. Hemodynamic instability during resection of pheochromocytoma in MEN versus nonMEN patients. Eur J Endocrinol. 2011 Jul. 165(1):91. 